\title{
The relationship between forest research and forest management in China: an analysis of four leading Chinese forestry journals
}

\author{
M. RUIZ PÉREZ`, M. FU", J. XIE", X. YANG" and B. BELCHER \\ - Department of Ecology, Faculty of Sciences, Universidad Autónoma de Madrid, Spain \\ - Research Institute of Subtropical Forestry, Chinese Academy of Forestry, Fuyang, Zhejiang, P. R. China \\ - Center for International Forestry Research, Bogor, Indonesia
}

Email: manuel.ruiz@uam.es

\begin{abstract}
SUMMARY
We analyse the collaboration between forestry research institutions and forestry departments in China based on a bibliometric study of four leading Chinese forestry journals. Multiple-authored papers are frequent, and there is a significant collaboration between research and implementing agencies. This collaboration centres on applied research, being less common on fundamental research and almost non-existent on policy research. Universities, National research institutes and National and Provincial level forest departments act as the key organisers of research, with specialised domains and types of collaboration. This helps explain the success of Chinese forestry experiences in recent years.
\end{abstract}

Keywords: forestry research, collaborative research, bibliometric, China

\section{INTRODUCTION}

A consensus has emerged that the combination of land, market and forest enterprise reforms, together with the recent emphasis on forest protection, has had a positive effect on the Chinese forestry sector, having been proposed as a model for other countries (Rozelle et al. 2000; Hyde, Belcher and Xu 2003). While major changes in policy have been normally considered at the base of this success (Albers et al. 1998; Bruce et al. 1995; Wang et al. 2004), little is known about the role of forestry research in the process of developing and implementing new policy measures.

Collaborative research between national and international forestry research institutions has been proposed as a way to reinforce links between different research agencies, to build local and national research capacities, to develop networks of joint-interest parties, and to influence the general forestry agenda (CIFOR 2004). Collaborative research between in-country institutions has received less attention. In this paper, we extend the international collaborative research assumptions to collaboration between Chinese institutions conducting forestry research. We analyse the connection between research institutions and forestry departments at different levels as an enabling factor that contributes both to policy design and its successful implementation in China.

\section{METHODOLOGY}

Tens of forestry research journals are currently published in China. We base our analysis on a bibliometric study of four leading Chinese forestry journals, selected as representatives of current national forestry research from different perspectives. The criteria for selection was the journal scope, the prestige of the institution that publishes it and the recognition as important journal among Chinese and foreign forestry specialists.

- Scientia Silvae Sinicae - SSS (Linye Kexue), the most important forestry journal in China, was established in 1955 by the Chinese Forestry Society. It is published bimonthly. It has a general scope and tends to publish academic and applied papers.

- Forest Research - FR (Linye Kexue Yanjiu), a national reference journal, started in 1988. It is a bimonthly publication of the Chinese Academy of Forestry. It focuses more on applied research.

- The Journal of Beijing Forestry University - BFU (Beijing Linye Daxue Xuebao) started in 1979. It is published bimonthly by the Editing Department of Journals of Beijing Forestry University. It tends to focus on academic papers.

- Forestry Economics - FE (Linye Jingii) was created in 1979. It is published monthly by the Research Cen- 
ter of Economic Development of the State Forestry Administration. It is the journal of reference for forestry socio-economic and policy research in China.

We reviewed all the papers published in the last five years (1999 to 2003), annotating authors' order of appearance and affiliations. These were grouped in eight main institutional categories, divided in two sub-groups. The first, for research institutions, inclu-ded National Research Institutes (NRI), Universities (UNIV), Provincial Research Institutes (PRI) and Other Research Institutes (ORI). The second included forestry management agencies of different sorts and at various levels: County Bureaus (B-county), City Bureaus (B-city), Provincial Departments (B-province) and National level Departments (B-national). Authors from private enterprises were included in this second group at the corresponding level (local, provincial or national) of their enterprises. A paper can have more than one affiliation given the frequency of multi-authored work published.

Based on the title, summary and keywords, papers were ascribed to one research category from applied forestry (silviculture, tree genetic improvement, and pest control), fundamental biological research (ecology, biology-physiology), social science research (socioeconomics, policy) and a general category of others that included a variety of subjects (production technology, machinery, management of production units, etc.).

Two basic assumptions guide our analysis: a) co-authored papers represent collaborative research; $b$ ) research collaboration between institutions represents interactions that facilitate their mutual influence. Based on these assumptions, we analyse below the structure of research and interactions between institutions by research subject categories.

\section{RESULTS AND DISCUSSION}

A total of 2855 articles were compiled, their number having increased steadily during the past five years (table 1). Universities (38.4\%) and National Research Institutes $(23.7 \%)$ are the dominant institutions accounting for almost $2 / 3$ of all authors' affiliations (table 2). However, there is a certain degree of specialisation by journal. Universities dominate the two more academic journal (BFU); universities are also predominant in SSS, that represents a combination of academic and applied research; National Research Institutes (notably those from the Chinese Academy of Forestry) lead in the more applied journal, FR; whereas National and Provincial (mainly Forestry) Departments tend to publish in the socio-economic and policy journal FE. This reflects a trend for in-house publishing, where university and NRI researchers tend to select the journals published by their respective institutions.
Single-author papers represent $25 \%$ of the articles; most work is co-authored, with an average of 3 authors per paper (figure 1a). The distribution varies by journal and research subject. The three general forestry journals (FR, BFU and SSS) have similar co-author distribution. FE stands as the journal with the lowest (1.6) level of co-authored articles. Social science research has a lower level of collaborative papers than the rest. Policy research represents an extreme case, with $71 \%$ of all papers as single-author (figure $1 \mathrm{~b}$ ).

Ecology as fundamental research and silviculture as applied research stand as the two main pillars of forestry research in the four journals selected (table 3). Socio-economic research also plays an important role, while policy research is the least frequent subject. Again there are important journal differences indicating the journal specialisation, particularly visible in the case of FE. Policy research is also the most journalspecific subject; 95 percent of all recorded policy research gets exposed and debated in FE, making this one of the key forest policy public forum debate in China.

Cooperation between different institutions is common in China's forestry research. In our sample, universities have the highest research inbreeding, with $67.3 \%$ of their papers published exclusively by university authors. They are followed by National level agencies (notably the State Forestry Administration) with $63.5 \%$ and National research institutes with $61.1 \%$. At the other extreme, city forest bureaus ( $47.5 \%$ ) and county forest bureaus (46.6\%), with the lowest percent of publications by members of the same institutions, tend to publish their papers in collaboration with different groups, mainly National research institutes and universities. This underscores the role of the two major research institutions as forestry research leaders, while the local forestry administration tends to have a dependent and complementary role. This interpretation is confirmed by the rate of senior authorship in publications. NRI (88.4\%) and universities ( $81.9 \%$ ) tend to dominate as first authors in the papers in which they participate, whereas senior authorship ratio is low in city bureaus (33.1\%) and county bureaus ( $24.2 \%$ ).

Co-authored work is particularly important when the cooperation is established between research institutions responsible for creating the knowledge and technology base and forestry departments at different levels responsible for forest management and policy development. This collaboration is a significant feature of forestry research in China. A total of $17.2 \%$ of the papers published in the reviewed journals are co-authored by staff from both type of institutions. Papers co-authored between research and management institutions are more frequent in applied research (pest control, tree improvement and silviculture, with approximately $25 \%$ of papers in these subjects being co-authored, see figure 2). Fundamental research (e- 
TABLE 1 Number of articles per journal and year of publication.

\begin{tabular}{lrccccc}
\hline \multirow{2}{*}{ Journal } & \multicolumn{5}{c}{ Year of publication } \\
\cline { 2 - 7 } & 1999 & 2000 & 2001 & 2002 & 2003 & Total \\
\hline Forest Research & 114 & 111 & 114 & 123 & 124 & 586 \\
Beijing Forestry University & 118 & 130 & 119 & 153 & 130 & 650 \\
Scientia Silvae Sinica & 146 & 152 & 141 & 176 & 210 & 825 \\
Forestry Economics & 75 & 101 & 173 & 214 & 231 & 794 \\
Total & $\mathbf{4 5 3}$ & $\mathbf{4 9 4}$ & $\mathbf{5 4 7}$ & $\mathbf{6 6 6}$ & $\mathbf{6 9 5}$ & $\mathbf{2 8 5 5}$ \\
\hline
\end{tabular}

TABLE 2 Frequency of institutions per journal

\begin{tabular}{lrrrrr}
\hline \multirow{2}{*}{ Institution } & \multicolumn{5}{c}{ Journal } \\
\cline { 2 - 6 } & \multicolumn{1}{c}{ FR } & BFU & \multicolumn{1}{c}{ SSS } & \multicolumn{1}{c}{ FE } & \multicolumn{1}{c}{ All } \\
\hline NRI & 425 & 83 & 316 & 118 & 942 \\
UNIV & 177 & 603 & 525 & 223 & 1528 \\
PRI & 63 & 24 & 99 & 27 & 213 \\
ORI & 50 & 91 & 27 & 6 & 174 \\
B-county & 105 & 35 & 76 & 69 & 285 \\
B-city & 47 & 21 & 35 & 39 & 142 \\
B-province & 35 & 8 & 44 & 105 & 192 \\
B-national & 59 & 62 & 72 & 308 & 501 \\
Total & $\mathbf{9 6 1}$ & $\mathbf{9 2 7}$ & $\mathbf{1 1 9 4}$ & $\mathbf{8 9 5}$ & 3977 \\
\hline
\end{tabular}

TABLE 3 Frequency of research subject per journal

\begin{tabular}{|c|c|c|c|c|c|}
\hline \multirow{2}{*}{$\begin{array}{l}\text { Research } \\
\text { subject }\end{array}$} & \multicolumn{4}{|c|}{ Journal } & \multirow{2}{*}{ Total } \\
\hline & FR & $\mathrm{BFU}$ & SSS & FE & \\
\hline policy & 3 & 4 & 4 & 210 & 221 \\
\hline biol-physiology & 58 & 83 & 99 & 0 & 240 \\
\hline tree improvement & 93 & 86 & 89 & 0 & 268 \\
\hline pest control & 105 & 39 & 125 & 2 & 271 \\
\hline socio-economic & 8 & 21 & 11 & 288 & 328 \\
\hline silviculture & 144 & 95 & 119 & 55 & 413 \\
\hline ecology & 86 & 155 & 208 & 47 & 496 \\
\hline others & 89 & 167 & 170 & 192 & 618 \\
\hline
\end{tabular}

FIGURE 1 Authors per paper (a) and percent of single author papers by subject.

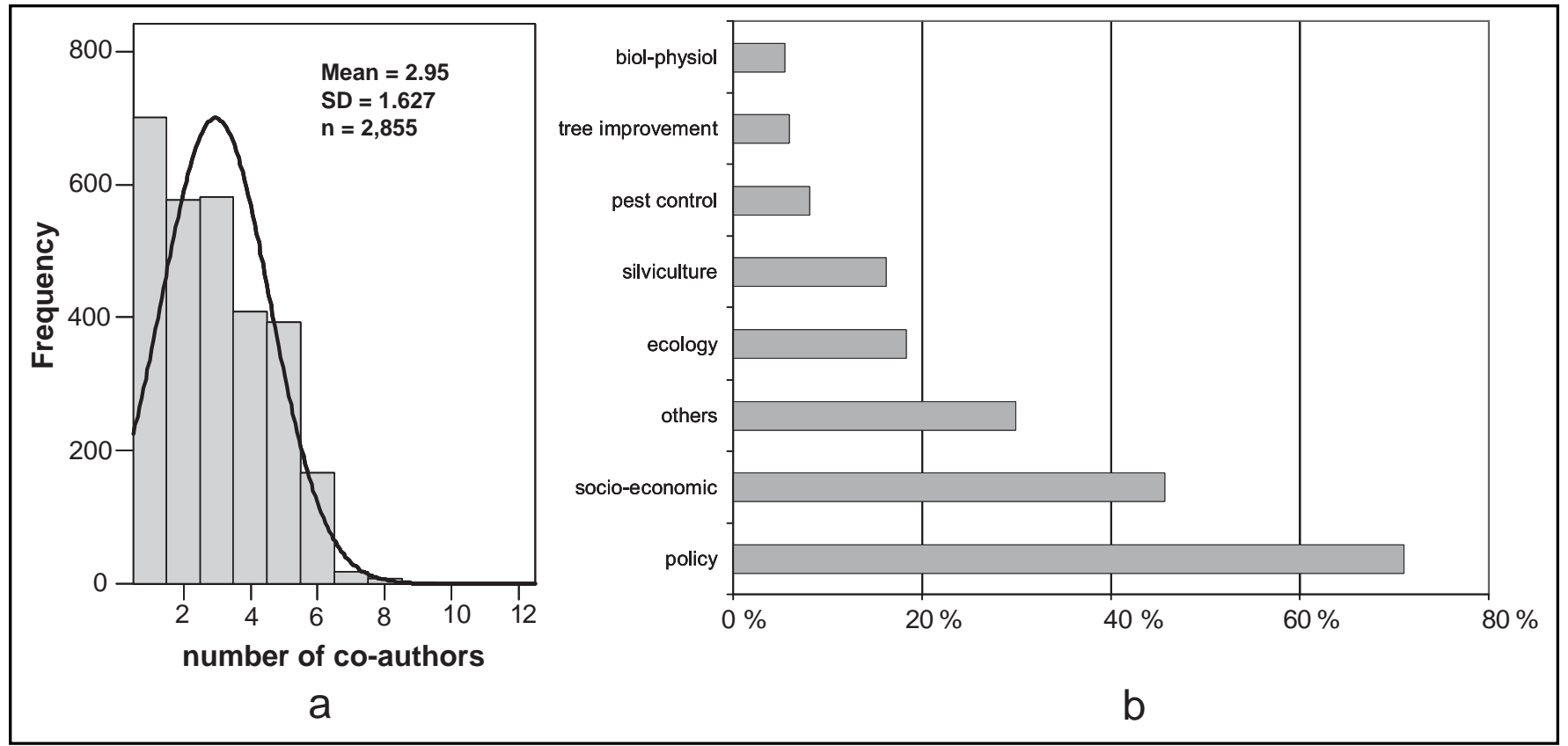

cology, biology-physiology) as well as socio-economic papers tend to have around $15 \%$ of the articles coauthored by authors of both research and management institutions. Finally, policy research, with only $4 \%$ of papers, is the domain where less collaboration between research and management takes place. It is also the domain where more papers are published by nonresearch institutions, notably National and Provincial level forest departments.

Two factors help explain this situation. First, many policy articles are policy discussion and preliminary proposal documents rather than policy research articles as such. Moreover, the policy-making process in Chinese forestry concentrates in the power-controlling agencies at National and Provincial level, where the basic forestry policy decisions take place. Thus, while collaborative work between research institutions and forestry departments is fundamental in China's forestry research and policy implementation activities, this collaboration seems to stop when dealing with the development of new policy measures and the discussion that precedes it, at least in public 
FIGURE 2 Percent of co-authored papers by subject

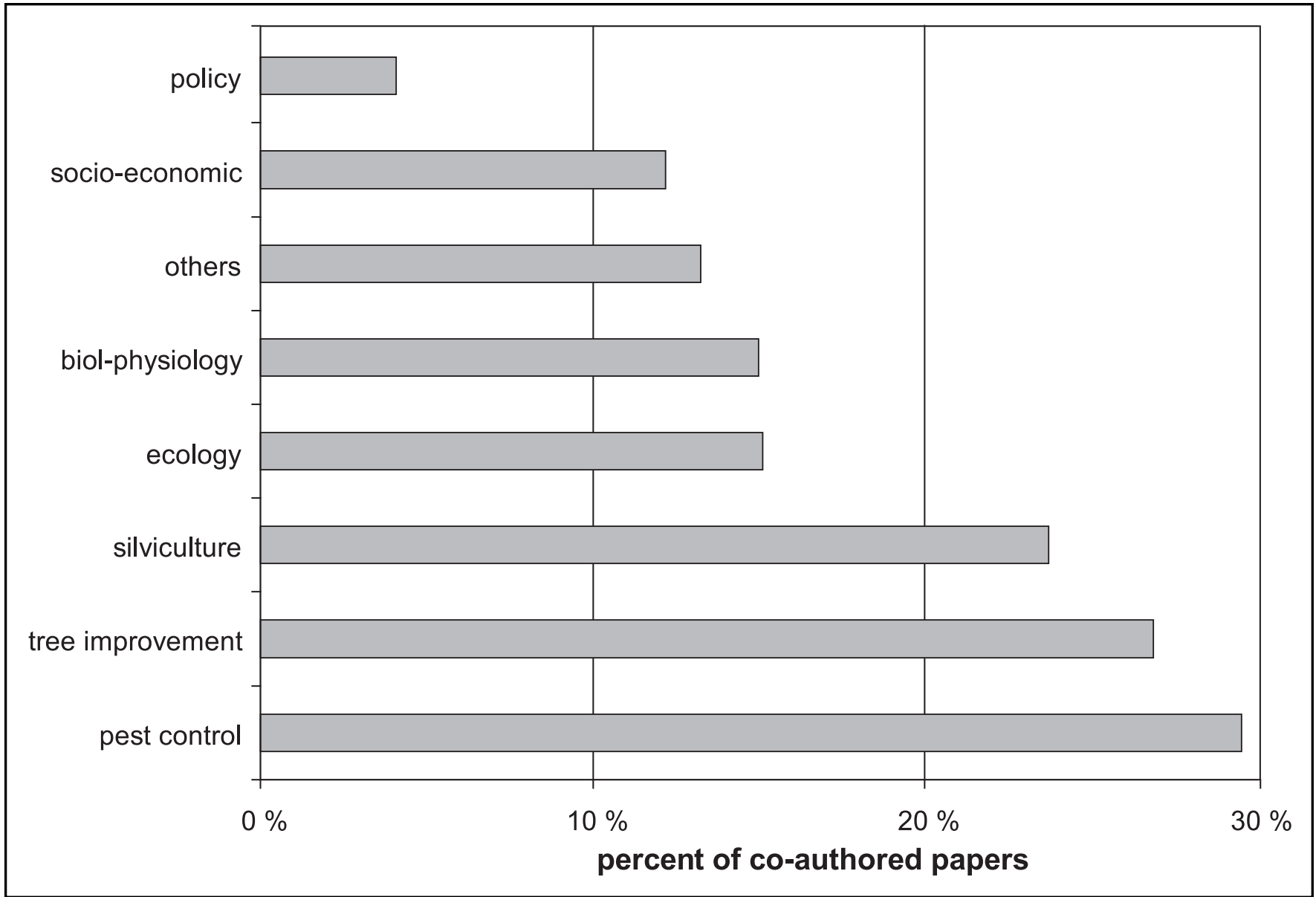

forum like forestry journals. This is particularly clear in the case of Forestry Economics, the journal published by the policy think-tank institution of the State Forestry Administration.

To conclude the study, we have conducted a principal components analysis of the cross-tabulation between research subjects and research institutions. The results of the first two axes (representing $89.9 \%$ of the total variance of the data) appear in figure 3 . This allows us to propose a three groups-structure of forestry research in China as represented by the publications in the four leading Chinese forestry journals selected.

- The first, organised around university teams, deals mainly with fundamental research (ecology, biology, physiology) having also some relation with socioeconomic subjects. This research tends to have a certain degree of inbreeding, although collaboration takes place also with other research institutions, mainly National research institutes.

- The second, organised around National research institutes, focuses on applied research, as well as on ecology and some socio-economic issues. This research has less inbreeding, having a functional collaboration with county, city and to a less extent provincial level forestry departments or bureaus.
- The third level corresponds to socio-economic and especially policy research, conducted by power-wielding, policy developing and implementing agencies at National and Provincial level, with little connection in what research is concerned with the rest of forestry players.

\section{CONCLUSIONS}

We have looked at Chinese forestry research through the window offered by four leading Chinese forestry journals. The degree of in-house publishing and journal specialisation introduce a certain bias in the sample and the results. At the same time, the importance of the journals selected and the institutions that publish them comprise sufficient breadth of outputs to represent adequately leading forestry research outputs in China. The inclusion of a more neutral journal like Scientia Silvae Sinicae, that also has the highest amount of papers in our sample, also helps to balance possible biases.

We identified institutional collaboration as a significant feature of this research. A special aspect of this collaboration is the joint work conducted between research and management agencies, particularly important in the case of applied research. This collaboration tends to be a functional relationship by 
FIGURE 3 Principal Components Analysis of the cross-frequency tabulation between research subject and research institutions.

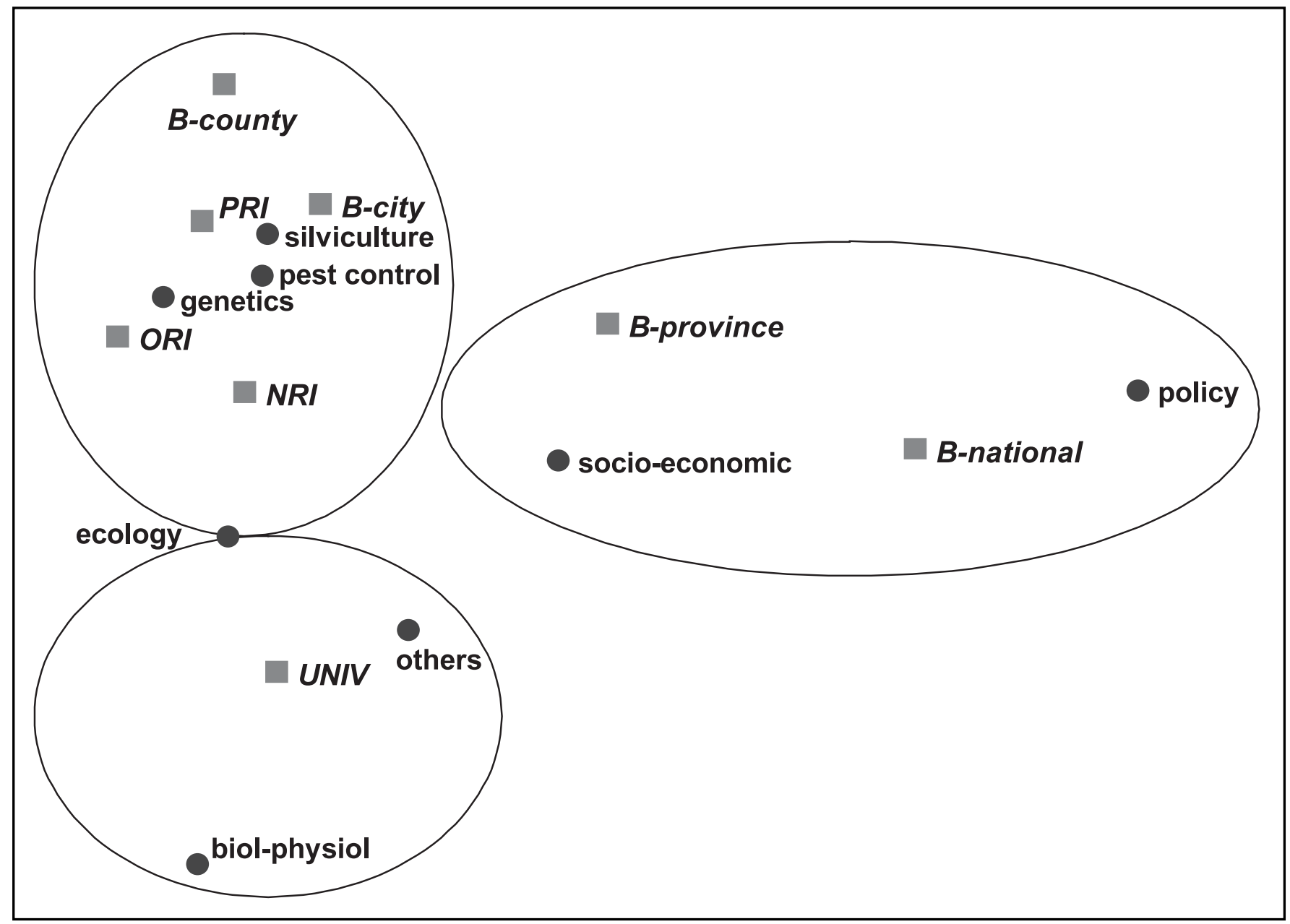

which research institutions get the expertise and empirical knowledge of the field offered by forest agencies (especially at local level) while maintaining the intellectual leadership of the research. In this sense, local forestry agencies act as efficient intermediaries between professional researchers and farmers, helping to explain the seemingly success of China's forest policies in recent times.

The collaboration recorded in these four journals, however, seems to stop at the level of social, particularly policy, research, both indicating a trend for tight control of the policy process, but also an opportunity for improved collaboration given the well established tradition in other research domains.

\section{REFERENCES}

ALBERS, H., ROZELLE, S. and GUO, L. 1998. China's forests under economic reform: timber supples, environmental protection and rural resource access. Contemporary Economic Policy 16:22-33.

BRUCE, J. W., RUDRAPPA, S. and ZONGMIN, L. 1995. Experimenting with approaches to common property forestry in China. Unasylva 46(180):44-49.
CIFOR. 2004. Science for Forests and People. CIFOR Annual Report 2003. CIFOR, Bogor, Indonesia.

HYDE, W. F., BELCHER, B., and XU, J. (eds). China's forests. Global lessons from market reforms. pp.1-21. Resources for the Future Press, Washington, D. C.

ROZELLE, S., HUANG, J., HUSAIN, S. A., and ZAZUETA, A. 2000. From afforestation to poverty alleviation and natural forest management: An evaluation of China's forest development and World Bank assistance. World Bank, Washington, D. C.

WANG, S., van KOOTEN, G.C. and WILSON, B. 2004. Mosaic of reform: forest policy in post-1978 China. Forest Policy and Economics 6:71-83. 